\title{
O INSTITUTO-GARANTIA DA CAUÇÃO AMBIENTAL E A COMPETÊNCIA LEGISLATIVA CONCORRENTE NA RELAÇÃO FEDERATIVO-CONSTITUCIONAL ENTRE O ESTADO DE MINAS GERAIS E A UNIÃO
}

\author{
Márcio Luís de Oliveira ${ }^{1}$ \\ Escola Superior Dom Helder Câmara (ESDHC) \\ Beatriz Souza Costa ${ }^{2}$ \\ Escola Superior Dom Helder Câmara (ESDHC)
}

\section{RESUMO}

O objetivo do artigo foi o de analisar a caução ambiental exigida nos processos de licenciamento das atividades socioeconômicas de mineração e uso de barragens. $\mathrm{O}$ estudo classificou juridicamente a caução ambiental como instituto-garantia de direitos difusos. Tal garantia se aplica ao dever de assistência e reparação por eventuais desastres ambientais e suas respectivas consequências humanitárias e culturais. O trabalho concluiu que, no âmbito da federação brasileira, há que prevalecer, em concreto, a norma específica estadual ou a norma-quadro federal que melhor atender aos princípios constitucionais da proteção mais efetiva e da subsidiariedade federativa. A metodologia utilizada na pesquisa foi dedutiva, analítica, dogmática e comparativa; e foram consultadas legislação nacional, estadual e estrangeira e textos bibliográficos específicos.

Palavras-chave: caução ambiental; desastre ambiental; mineração; princípio da proteção mais efetiva; princípio da subsidiariedade federativa.

\footnotetext{
1 Doutor e Mestre em Direito pela Universidade Federal de Minas Gerais (UFMG). Aperfeiçoamento em Direito Internacional Público e Privado pela Academia de Direito Internacional de Haia (ADIH). Graduado em Direito pela UFMG. Professor da Faculdade de Direito da UFMG, da ESDHC (Mestrado/Doutorado) e da Faculdade Milton Campos (Mestrado). Professor visitante na Universidad Complutense de Madrid (UCM). Professor colaborador na The Hague University of Applied Sciences. Consultor-Geral da Consultoria Técnico-Legislativa do Poder Executivo do Estado de Minas Gerais. ORCID: https://orcid.org/0000-0001-7437-0766 / e-mail: marcio.luis@uol.com.br

2 Pós-doutora pela Universidad Castilla-La Mancha. Doutora e mestre em Direito Constitucional pela Universidade Federal de Minas Gerais (UFMG). Professora na Pós-graduação em Direito Ambiental e Desenvolvimento Sustentável da ESDCH e Pró-reitora de Pesquisa da ESDHC. ORCID: https:// orcid.org/0000-0003-0636-6081 / e-mail: biaambiental@yahoo.com.br
} 
THE ENVIRONMENTAL BOND: THE STATE LAW OF MINAS GERAIS AND THE FRAMEWORK LAW OF THE UNION FROM THE PERSPECTIVE OF THE BRAZILIAN FEDERAL STATE

\section{ABSTRACT}

The objective of the essay was to analyze the environmental bond required in the licensing processes for economic mining activities and the use of dams. The study legally classified the environmental bond as a guarantee for diffuse rights. Such guarantee applies to the duty of assistance and repair for possible environmental disasters and their respective humanitarian and cultural consequences. The work concluded that, within the scope of the Brazilian federation, the specific state law or the federal framework law that best meets the constitutional principles of the most effective protection and federal subsidiarity must prevail. The methodology used in the research was deductive, analytical, dogmatic and comparative; and national, state and foreign legislation and specific bibliographic texts were consulted.

Keywords: environmental bond; environmental disaster; mining; principle of the most effective protection; principle of subsidiarity; environmental law. 


\section{INTRODUÇÃO}

A atividade socioeconômica da mineração e a utilização de barragens de resíduos são muito peculiares à dinâmica social, econômica, política e jurídica das Minas Gerais. Parte da formação identitária mineira resulta da histórica ocupação e povoamento das regiões montanhosas do seu território por bandeirantes, manufatureiros, trabalhadores, escravos, comerciantes e tropeiros que atuaram em alguma atividade relacionada às minas e à metalurgia. As principais cidades históricas do Estado como Ouro Preto, Mariana, Congonhas, Tiradentes e Diamantina se formaram e sempre se conectaram com esses setores da economia em suas diversas expressões culturais e institucionais. A herança colonial advinda da urbanização em torno das minas de ouro, diamante e ferro, dentre outras tantas, constitui um imenso acervo cultural do povo mineiro e brasileiro.

Mas, ainda que seja parte constitutiva da "mineiridade", a atividade de mineração e seus desdobramentos estruturais, como as barragens de resíduos, também deixaram marcas históricas de imenso sofrimento humano e degradação ambiental e cultural. Os dois últimos acontecimentos de maior expressão em relação a essas questões dizem respeito aos desastres advindos do rompimento de barragens de resíduos da mineração nos municípios de Mariana, em 2015, e Brumadinho, em 2019. Esses dois desastres alcançaram repercussão na mídia global e deixaram no registro da história de Minas Gerais um triste legado de centenas de vítimas, extensos danos ambientais, perda de patrimônio histórico inestimável e economias locais e regionais depauperadas. Um desses desastres teve consequências para muito além das montanhas e dos vales de Minas e atingiram o povo e o território do Estado do Espírito Santo.

Entre culpados e inocentes, uma conclusão se pode aferir do ocorrido: a urgente necessidade de um marco legal que pudesse estabelecer parâmetros para a imediata e efetiva assistência financeira em casos de rompimentos de barragens, em especial em áreas densamente povoadas e de imenso acervo ambiental e cultural. Foi nesse contexto que, logo após o desastre de Brumadinho, em 2019, mas já idealizada desde o caso de Mariana, em 2015, que o Estado de Minas Gerais editou a Lei no 23.291, de 25 de fevereiro de 2019, com o objetivo de aperfeiçoar a política estadual de segurança de barragens.

Os aspectos acima abordados justificam a elaboração do presente artigo a partir do seu tema-problema, hipóteses, marco teórico, objetivos, metodologia, organização do conteúdo e considerações finais. 
Um dos institutos inovadores desse marco legal regional é a chamada caução ambiental. Considerada a positivação do instituto, este artigo se assenta sob o seguinte tema-problema: qual é o conceito e o alcance normativo do instituto da caução ambiental previsto na legislação estadual de Minas Gerais?

Por ser a caução ambiental uma garantia jurídica positivada originariamente em norma estadual com conexões em várias especialidades do Direito, o marco teórico-dogmático do artigo assenta-se no instituto constitucional da competência legislativa concorrente entre os entes Federativos. Assim, como hipóteses, o artigo se propõe a aferir: a) a maior ou a menor extensão da titularidade e do exercício dessa competência legislativa concorrente pelo Estado de Minas Gerais em relação à caução ambiental; b) a eventual suspensão ou não da eficácia da norma estadual na perspectiva de positivação de norma geral nacional sobre a matéria.

Nesse sentido, o artigo tem por objetivo geral discorrer sobre a competência legislativa estadual concorrente no tema da caução ambiental. Como objetivo específico, o artigo busca investigar as modalidades da competência legislativa concorrente entre os entes da Federação e sua eficácia no âmbito do Direito ambiental, mais especialmente na instituição e regulação da caução ambiental.

A metodologia utilizada na pesquisa foi dedutiva, tendo sido utilizados os métodos analítico-dogmático, analítico-conceitual, analítico-descritivo e elementos básicos do método comparativo. Como fontes primárias, a pesquisa se pautou pela consulta à legislação nacional, estadual e estrangeira e, como fontes secundárias, o acesso a acervos bibliográficos, tais como livros e artigos disponibilizados em revistas científicas, inclusive via rede mundial de computadores.

Em síntese, o artigo - além da introdução, das considerações finais e das referências bibliográficas - foi organizado em dois tópicos. No primeiro, foi abordado o instituto constitucional da competência legislativa concorrente entre os entes da Federação brasileira, em comparação básica com a mesma competência prevista no regime constitucional da República Federal da Alemanha, de onde o instituto se originou. No segundo item, o artigo tratou do tema da caução ambiental prevista na legislação estadual de Minas Gerais, como instituto-garantia em face de desastres ambientais advindos de rompimentos ou vazamentos de barragens, especialmente no campo da atividade socioeconômica da mineração. 


\section{A COMPETÊNCIA LEGISLATIVA CONCORRENTE ENTRE OS ENTES FEDERATIVOS: CONCEITOS, TITULARIDADES, EXERCÍCIO E EFICÁCIA NORMATIVA}

A forma federativa de Estado adotada pela vigente Constituição brasileira é por demais complexa e ineficiente quanto à modelagem da atribuição de funções estatais aos entes federativos, em especial as de natureza legislativa, administrativa e de fiscalização. No âmbito do Direito Ambiental - e pelas repercussões federativas, ambientais, econômicas, sociais, humanitárias e jurídicas das suas especificidades - o regime constitucional de competências se revela improfícuo. Logo, não gera segurança jurídica e nem eficácia contextual.

Na seara do Direito Ambiental, este artigo se foca nas modalidades da competência legislativa concorrente entre os entes da Federação para fins de análise do regime jurídico incidente sobre o instituto da caução ambiental em relação à utilização de barragens na atividade de mineração.

A concepção jurídica da competência legislativa concorrente advém da Lei Fundamental da República Federal da Alemanha, em 1949. Contudo, desde suas origens, o conteúdo e a extensão dessa competência têm sido aperfeiçoados por reformas constitucionais e por precedentes do Tribunal Constitucional Federal (HORBACH, 2015).

O pressuposto para a positivação da competência legislativa concorrente é a pluralidade de entidades estatais federativas dotadas de função legislativa para regular matéria jurídica que lhes seja, concomitante e especificamente, afetas em níveis local, regional e transregional (HORTA, 2010, p. 324). Assim, considerada a possibilidade de multiplicidade de regimes jurídicos sobre o mesmo tema e a sua potencialidade de repercussão simultânea e antinômica em mais de uma entidade federativa, a competência legislativa concorrente baseia-se em três premissas convergentes: a) a competência de um dos entes federativos para, no campo da positivação das normas gerais nacionais (ATALIBA, 2011, p. 291), uniformizar conceitos, princípios, processos, estruturas, instituições, funções, direitos, deveres e garantias básicos em determinada matéria jurídica, a serem observados por todos os entes da Federação no exercício de suas competências legislativas específicas; b) a competência de cada ente federativo para regular suas especificidades conjunturais, institucionais e funcionais quanto à matéria objeto das normas gerais nacionais; c) critérios hermenêuticos de solução de antinomias entre as normas gerais nacionais e as normas específicas 
(federais, estaduais, distritais e municipais).

Constata-se, pois, que a competência legislativa concorrente tem respaldo no princípio da subsidiariedade como norma estruturante do modelo federativo de Estado. Segundo Oliveira,

[...] o 'princípio da subsidiariedade' - na organização das competências constitucionais da Federação (União, Estados-Membros, Distrito Federal e Municípios) - assenta-se nas seguintes premissas: a) determinado interesse público da sociedade deve ser prioritariamente atribuído à competência do ente federativo que tiver melhores condições fáticas, orçamentárias e jurídicas para realizá-lo; e b) a titularidade e/ou exercício da competência para satisfazer o interesse público só devem ser subsidiariamente transferidos para a competência de outro ente da Federação caso aquele que a detiver com prioridade constitucional não tiver condições ou não puder satisfazê-lo a contento, ou, num dado contexto, não dever realizá-lo, ou, ainda, houver autorização constitucional para a atuação conjunta dos entes federativos, observado o critério da prioridade (OLIVEIRA, 2016, p. 376).

Como primeira premissa, observa-se que, nos modelos federativos que adotam a competência legislativa concorrente, as normas gerais nacionais de uniformização competem à entidade federativa que, por delegação constitucional, presenta o Estado em âmbito macronacional. No sistema brasileiro, essa competência é atribuída à União, conforme artigo 24, caput, $\S 1^{\circ}$, da Constituição da República Federativa do Brasil (CRFB). Ressalta-se que a União, no exercício dessa competência, não edita normas federais para tratar de matérias de sua atribuição própria, mas normas gerais nacionais para abarcar temas de desdobramentos em todos os entes da Federação (União, Estados-Membros, Distrito Federal e Municípios) em suas especificidades e competências diversas. Nesses termos, e ao distinguir as normas nacionais das federais, Ataliba ressalta que

[...] a lei nacional é muito mais ampla e, como dito, transcende às distinções estabelecidas em razão das circunscrições políticas e administrativas.

A lei nacional, categoria jurídico-positiva diversa, é o produto legislativo do Estado nacional, total, global.

Vige no território do Estado brasileiro, vinculando todos os sujeitos à sua soberania, abstração feita de qualidades outras que possam revestir. Esta lei faz abstração da circunstância de ser o Brasil estado unitário ou federal.

Em têrmos práticos, a lei federal se opõe à lei estadual e à municipal, enquanto que a lei nacional abstrai de tôdas elas — federal, estadual e municipal — transcendendose.

$[\ldots]$

Leis federais são aquelas que podem ser editadas, no campo próprio, pela União. Da mesma forma, nos respectivos campos, são leis estaduais e municipais as editadas 
por Estados e Municípios, cada qual na própria esfera de competência [...] [e] estão, no mesmo nível, equiparadas, as leis próprias das diversas pessoas públicas políticas. (ATALIBA, s.d., p. 49)

A partir dessa diferenciação entre norma nacional e norma federal, pode-se aferir, por exemplo, a competência da União para legislar - por meio de lei federal - sobre temas jurídicos que lhes são constitucionalmente próprios, como os Direitos Civil, Penal, Eleitoral e do Trabalho (competências legislativas exclusivas ou privativas, por exemplo). Paralelamente, a União também tem competência para legislar - por intermédio de lei geral nacional, via competência legislativa concorrente - em matérias jurídicas que são constitucionalmente conferidas a todos os entes da Federação, em alguma especificidade. Nessa seara, podem ser citados os Direitos Ambiental, Tributário, Financeiro-Orçamentário e Econômico. Por conseguinte, a competência legislativa concorrente da União para positivar normas gerais nacionais coexiste com as competências específicas de todos os entes da Federação para também editar normas afetas à matéria jurídica objeto da norma geral nacional. É nesse contexto que se pode observar a concomitância do Código Tributário Nacional (lei geral nacional) com as leis tributárias específicas federais, estaduais, distritais e municipais em relação aos respectivos tributos de competência exclusiva.

Por sua vez, e como segunda premissa, a competência concorrente para a edição de normas específicas é conferida a cada ente federativo, com as devidas particularidades, e sob duas perspectivas distintas, quais sejam: a) a competência legislativa concorrente suplementar ou complementar; b) a competência legislativa concorrente supletiva ou de integração (integrativa).

A competência legislativa concorrente suplementar ou complementar é atribuída aos entes regionais da Federação (ou até locais, no modelo federativo brasileiro) para adequarem as normas gerais nacionais às especificidades de suas conjunturas, instituições e funções em níveis regional ou local. Por seu turno, a competência legislativa concorrente supletiva ou integrativa também é atribuída aos entes regionais ou locais da Federação para editarem normas de integração com a finalidade de suprirem omissões temáticas em relação às normas gerais nacionais. No Direito brasileiro, essas duas competências legislativas concorrentes são de titularidade expressa dos Estados e Distrito Federal e, por hermenêutica constitucional ${ }^{3}$, dos

3 Supremo Tribunal Federal (STF), Plenário, RE $\mathrm{n}^{\circ} 1020307$ SP, Município de Sorocaba, Relator Ministro Luiz Fux, julgamento em 31/3/2017, DJe-068 5/4/2017. 
Municípios, nos termos do artigo 24 , caput, $\S \S 2^{\circ}$ e $3^{\circ}$, artigo 30 , incisos I e II, e artigo $32, \S 1^{\circ}$, da CRFB.

Há, ainda, uma terceira premissa. O regime de competência legislativa concorrente também deve fixar critérios hermenêuticos de solução de antinomias entre as normas gerais nacionais e as normas específicas (federais, estaduais, distritais e municipais). Entretanto, no Direito brasileiro nem todas as normas gerais nacionais tratam desse aspecto, o que acaba permitindo a ocorrência de muitas antinomias e erros hermenêuticos e de aplicação. O Código Tributário Nacional é uma exceção ao fixar minimamente alguns parâmetros hermenêuticos em seus artigos 107 a 112 e a serem observados por todos os entes da Federação no exercício de suas competências tributárias específicas. Observa-se que a própria União, ao regular os tributos federais de sua competência legislativa exclusiva, deve se pautar pelas diretrizes estabelecidas na norma geral nacional, que fora positivada também pela União, mas no âmbito da competência legislativa concorrente.

Mas, no Brasil, a precariedade de previsibilidade de critérios hermenêuticos já decorre da própria Constituição. No seu artigo 24 só há duas regras genéricas de hermenêutica para se solucionar antinomias no campo das competências legislativas concorrentes. São elas os $\S \S 1^{\circ}$ e $4^{\circ}$ do referido artigo:

Art. 24. Compete à União, aos Estados e ao Distrito Federal legislar concorrentemente sobre:

$[\ldots]$

$\S 1^{\circ}$ No âmbito da legislação concorrente, a competência da União limitar-se-á a estabelecer normas gerais.

$[\ldots]$

$\S 4^{\circ}$ A superveniência de lei federal sobre normas gerais suspende a eficácia da lei estadual, no que lhe for contrário.

A primeira norma hermenêutica é muito vaga ao não conceituar exatamente o conteúdo do que seriam as "normas gerais" de competência concorrente da União. E a segunda norma apenas estabelece qual dispositivo ou diploma legal deve prevalecer na hipótese de antinomia entre a norma geral nacional editada pela União e as normas estaduais, distritais e municipais.

Há ainda omissão em relação ao alcance de eventual norma federal específica para tratar de tema afeto apenas à competência legislativa da União e que também é objeto da norma geral nacional. A título de exemplo, o Código Tributário Nacional (norma geral nacional) coexiste com a legis- 
lação federal relativa apenas aos tributos federais. Ou seja, a competência legislativa concorrente para normas gerais nacionais se aplica, em suas diretrizes, à União - no campo de suas competências legislativas específicas - tanto quanto aos Estados-membros, Distrito Federal e Municípios. O artigo 24, entretanto, nada prevê nas circunstâncias em que a União ultrapassa os limites de conteúdo de normas gerais nacionais e adentra em especificidades que são de interesse jurídico apenas dela ou, ainda pior, dos demais entes da Federação. Isso ocorre pela vagueza do dispositivo constitucional previsto no $\S 1^{\circ}$ do artigo 24 da Constituição.

Na hipótese do $\S 4^{\circ}$ do artigo 24 , a solução de antinomia de normas concorrentes suplementares ou de integração dos Estados-membros em relação às normas gerais nacionais é pouco resolutiva; e é agravada pela vagueza do conceito de normas gerais nacionais e pela inexistência de delimitação constitucional mais precisa da competência legislativa concorrente da União.

Em contrapartida, e ainda que apresente lacunas, o sistema alemão que serviu de modelo ao Brasil na questão das competências legislativas concorrentes prevê mecanismos mais específicos para a solução de eventuais antinomias. Ao tratar da reforma constitucional alemã de 2006, HORBA$\mathrm{CH}$, afirma que

A partir daí, a Alemanha passou a contar com três modalidades de competências legislativas concorrentes: as competências básicas (Kernkompetenzen), do art. 72, I, LF; as competências necessárias (Bedarfskompetenzen), art. 72, II, LF, e, finalmente, as competências de divergência (Abweichungskompetenzen).

O ponto mais instigante da reforma foi a introdução dessa última (da competência de divergência), sistema de distribuição de competências legislativas que institui técnica completamente inovadora no Direito alemão - quiçá mundial. O art. 72, III, LF concedeu aos Estados a possibilidade de elaboração de regras próprias e divergentes à legislação federal que possam atender de forma mais efetiva suas necessidades e características locais, em determinadas matérias.

Uma lei estadual divergente não revoga a lei federal divergida no âmbito do seu respectivo território estadual, mas passa a ter uma "prioridade de utilização" (Anwendungsvorrang), ou seja, passa a valer antes daquela (geht vor). Essa questão deixa claro que, com eventual revogação da norma estadual divergente, a lei federal automaticamente passa a valer nesse Estado. Por outro lado, quando a União legislar sobre essas matérias, após a divergência estadual, passa essa lei federal a ter prioridade em relação às leis estaduais divergentes, por ser lei posterior.

Essa possibilidade de que lei federal passe a ter prioridade de utilização em relação a leis estaduais divergentes de mesmo conteúdo, e que os Estados possam novamente divergir das leis federais que foram contrárias a suas antigas leis estaduais válidas, 
é mecanismo apelidado de efeito ping-pong pelos doutrinadores alemães, já que poderia gerar um "vai e vêm" infinito entre legislação federal e estadual. Todavia, apontam, trata-se de hipótese teórica, uma vez que o próprio princípio da fidelidade federativa (Bundestreue), tão arraigado na cultura constitucional alemã, seria, por si só, um freio para tal situação.

A introdução do direito de divergência também afetou outra clássica regra do federalismo germânico, constantemente citada entre nós: a ideia de que, colidindo normas do direito federal com estaduais, as leis federais têm preferência em relação às estaduais - princípio emanado do art. 31, LF (Bundesrecht bricht Landesrecht). No campo da legislação concorrente divergente, é válido não mais o princípio da superioridade (Superioritätsgrundsatz) ou da primazia do direito federal, mas sim o princípio da posterioridade (Posterioritätsgrundsatz). (HORBACH, 2015)

Logo, no sistema alemão, o ente federativo regional competente para atuar nas especificidades conjunturais detém a preferência constitucional para regular o tema, observadas as competências da Federação para positivar as normas concorrentes básicas, necessárias e de divergência, nos termos previstos no artigo 72 da Lei Fundamental da República Federal da Alemanha ${ }^{4}$.

O tema das competências legislativas concorrentes é de especial relevo na matéria ambiental, objeto, em parte, deste artigo. No Direito Ambiental, o sistema alcança imensa complexidade; sobretudo porque é dotado de transdisciplinaridade temática, conceitual, institucional, funcional e conjuntural.

No contexto deste artigo, passa-se à análise da titularidade e exercício da competência legislativa concorrente exercida pelo Estado de Minas Gerais no processo de positivação do instituto da caução ambiental.

4 Artigo 72 [Legislação concorrente]

(1) No domínio da legislação concorrente, cabe aos Estados a faculdade de legislar, enquanto e na medida em que a Federação não faça uso, através de lei, da sua competência legislativa.

(2) Em matéria concernente ao artigo 74 §1, alíneas 4, 7, 11, 13, 15, 19a, 20, 22, 25 e 26, a Federação tem o direito de legislação, quando e na medida em que se fizer necessário um regulamento legislativo federal, no interesse do Estado em seu todo, para o estabelecimento de condições equivalentes de vida no território federal ou a preservação da unidade jurídica ou econômica.

(3) Se a Federação fizer uso da sua competência legislativa, os Estados podem adotar, por lei, regulamentos distintos sobre:

1. a caça (sem o direito de expedir licença de caça);

2. a proteção da natureza e a preservação da paisagem (sem os princípios gerais da proteção da natureza, o direito de proteção das espécies ou da proteção da natureza marítima);

3. a distribuição do solo;

4. a estruturação do território;

5. o regime hidráulico (sem regulamentos referentes a substâncias ou instalações);

6. a admissão às universidades e os certificados de conclusão das universidades.

Leis federais nestas matérias só entrarão em vigor seis meses após a sua promulgação, salvo determinação distinta com a aprovação do Conselho Federal. Nas matérias da primeira frase, prevalece, na relação entre Direito federal e estadual, a lei respectivamente mais recente.

(4) Por lei federal pode ser determinado que um regulamento legal da Federação, não mais necessário de acordo com o §2, possa ser substituído por legislação dos Estados. 


\section{A POSITIVAÇÃO DO INSTITUTO-GARANTIA DA CAUÇÃO AMBIENTAL NO ÂMBITO DO REGIME JURÍDICO DO ESTADO DE MINAS GERAIS}

No Brasil, o Direito Ambiental é afeto a todos os entes da Federação; e a previsão básica de sua regulação insere-se no âmbito das competências legislativas concorrentes (artigo 24, incisos VI, VII e VIII, da Constituição). Dentre suas especificidades se encontra a atividade de mineração e, mais especialmente, o tema das barragens utilizadas nesse setor socioeconômico extrativista. Em tal conjuntura, a legislação primária e regulamentar é abundante em todos os níveis da Federação.

Contudo, em Minas Gerais, onde a atividade de mineração se identifica com a própria historicidade da formação da sociedade e do Estado mineiros, além da enorme dependência socioeconômica dos setores a ela correlacionados, a legislação estadual é minuciosa, complexa e extensa. $\mathrm{O}$ contexto normativo se torna ainda mais relevante se considerados os dois últimos desastres advindos da atividade de mineração e que causaram grande repercussão humanitária, ambiental e cultural a partir das localidades onde aconteceram: os Municípios de Mariana, em 2015, e de Brumadinho, em 2019.

Desde suas ocorrências, os dois desastres têm sido administrados de formas muito distintas; e seus desdobramentos humanitários, ambientais, culturais e socioeconômicos ainda não são compreendidos em totalidade (KOKKE; OLIVEIRA, 2017).

Porém, dentre as diversas medidas públicas e privadas adotadas para minimizar seus efeitos, responsabilizar os agentes envolvidos e evitar a repetição de eventos semelhantes, destaca-se, neste artigo, a edição da Lei Estadual $\mathrm{n}^{\circ}$ 23.291, de 25 de fevereiro de 2019, que alterou a política estadual de segurança de barragens, superando e aperfeiçoando a legislação que lhe antecedia, em especial a Lei Estadual $n^{\circ} 15.056$, de 31 de março de 2004, e, em parte, a Lei Estadual no 20.009, de 4 de janeiro de 2012.

Sem se adentrar nas questões concernentes ao seu processo legislativo e anteriores ao desastre de Brumadinho, a Lei Estadual n $n^{0} 23.291$, de 2019, teve sua conclusão realizada em curto tempo, e logo após o fato. Sob sua regência, os agentes socioeconômicos que se utilizam de barragens no setor de mineração passaram a ser submetidos a maior fiscalização, responsabilização e sancionamento administrativos, além do dever de observância de critérios técnicos mais rígidos de licenciamento ambiental, construção, 
manutenção, operacionalidade, descaracterização e até de regras impeditivas em relação à modalidade de barragens alteadas pelo método a montante (que deverão ser substituídas por meios tecnológicos alternativos de acumulação ou disposição de rejeitos e resíduos, acompanhadas de descaracterização das respectivas barragens ainda existentes).

Mas dentre as principais inovações da Lei Estadual $n^{\circ} 23.291$, de 2019, uma merece destaque: a previsão de proposta de caução ambiental por parte do empreendedor, estabelecida em regulamento, com o propósito de garantir a recuperação socioambiental para casos de sinistro e para desativação da barragem, durante o processo de licenciamento ambiental, e para fins de concessão da licença prévia (artigo $7^{\circ}$, inciso I, alínea "b"). Por sua vez, na obtenção da licença de operação, passou a ser obrigatória a comprovação, pelo empreendedor, da implementação da caução ambiental, com a devida atualização (artigo $7^{\circ}$, inciso III, alínea "b").

A discussão acerca da caução ambiental para empreendimentos socioeconômicos classificados como de potencial risco de dano ambiental, humanitário e patrimonial-cultural não é nova. Trata-se de instituto já utilizado em alguns sistemas jurídicos, e em variadas modelagens, como na Nova Zelândia, Austrália e Canadá. Ao versar sobre os elementos de comando-e-controle (regulação direta) e os instrumentos econômicos (regulação indireta) como mecanismos a serem considerados nas etapas de elaboração, tomada de decisão, implementação e avaliação de políticas públicas capazes de conjugar as atividades socioeconômicas com a proteção ambiental, Windham-Bellord insere o instituto da caução ambiental na segunda categoria e sustenta que

Para realizar a internalização destas questões e a responsabilização das pessoas que causaram o dano, pode-se utilizar uma série de instrumentos de regulação direta (também conhecidos como comando e controle) e indireta (instrumentos de mercado). Exemplos de comando e controle são: padrões de emissão de poluentes, licenciamentos, estudos de impacto, zoneamento, sanções administrativas e penais. Exemplos de instrumentos econômicos são: incentivos econômicos, subsídios, tributos, sistema de cobrança pelo uso de recursos ambientais, sistemas de depósito e retorno, certificados transacionáveis, seguro e caução ambiental. Tais mecanismos são utilizados como indutores de comportamentos desejados para os empreendedores e para alcançar os objetivos da política nacional de meio ambiente. Conforme Mendes e Seroa da Motta, instrumentos econômicos são orientados para o mercado e combinam elementos referentes a regulamentos e incentivos econômicos para alcançar a proteção ambiental. (WINDHAM-BELLORD, 2015, p. 146) 
Apesar de se tratar de um instituto conhecido internacionalmente, o sistema jurídico brasileiro não havia utilizado da caução ambiental como objeto de norma geral nacional. Sob essa perspectiva, o Estado de Minas Gerais, ao editar a Lei Estadual no 23.291, de 2019, aperfeiçoou o Direito Ambiental brasileiro por intermédio da competência legislativa concorrente supletiva ou de integração. Ao positivar essa modalidade de instituto-garantia como instrumento de política pública para empreendimentos de risco ambiental-humanitário-cultural, Minas Gerais efetivamente tratou de modo pleno e de maneira a atender suas peculiaridades, posto que é o Estado da Federação que historicamente se desenvolveu em torno da atividade de mineração e de suas derivações estruturais (ex.: as barragens de rejeitos) e industriais (como as atividades de beneficiamento de minério, de aciaria e automobilísticas), além de ser fortemente dependente desses setores sob as perspectivas socioeconômica e fiscal-orçamentária.

Ademais, parte substancial da atividade de mineração no Estado de Minas Gerais está localizada em região densamente povoada e com imenso acervo histórico-cultural e ambiental, qual seja, o quadrilátero ferrífero, onde se situa a capital Belo Horizonte e seu entorno macrorregional. Esse fator torna ainda mais evidente as peculiaridades do Estado de modo a justificar a titularidade e o exercício das suas competências legislativas concorrente suplementar e concorrente de integração, nos termos do artigo $24, \S \S 2^{\circ}$ e $3^{\circ}$, da Constituição. Logo, a previsão dessa matéria em norma geral nacional editada pela União não gera, por si só, antinomia a justificar a suspensão de eficácia da lei estadual mineira, bem como de sua decorrente regulamentação. Mesmo que a lei geral nacional venha a regular detalhadamente esse tema, a realidade do Estado de Minas Gerais em relação à atividade de mineração é bastante peculiar se comparada a outros Estados-membros da Federação. Até mesmo no Estado do Pará, onde a atividade de mineração tem sido fortalecida, o adensamento populacional e o acervo histórico-cultural nas regiões mineradoras são muito distintos de Minas Gerais, ainda que se considere a riqueza de outro meio ambiente natural igualmente passível de sofrer com os eventuais riscos de desastre, como é caso da região amazônica.

Contudo, o instituto-garantia da caução ambiental não é de fácil implementação regulatória e nem de execução administrativa. Isso ocorre por inúmeros motivos, a começar pelas modalidades de garantias e as metodologias de cálculo, bem como os respectivos processos de integralização, liberação, atualização e etapas de aplicação (TORQUETTI; SAWAYA; 
VEIGA, 2014). Somado a esses fatores, o alto custo econômico-financeiro das cauções ambientais - decorrentes de suas distintas potencialidades de desastres - é outro importante aspecto a ser considerado, sob pena de ineficácia do instituto. As políticas públicas de proteção do meio ambiente e de adoção de medidas para a sua recuperação em face do risco do empreendimento devem ser acompanhadas de mecanismos de estímulos às atividades socioeconômicas sustentáveis que, em grande maioria, são financeiramente muito caras para alguns setores e atores. Ressalta-se que a omissão ou a precariedade quanto à inclusão de medidas socioeconomicamente viáveis na pauta das políticas públicas ambientais são fatores desestabilizadores da própria proteção ambiental, uma vez que o desemprego estrutural e a pobreza geram instabilidade institucional e social com efeitos adversos.

Todos esses aspectos levam a se pensar o instituto da caução ambiental na seara de conexões das Ciências Atuariais com a Ciência da Administração Pública e de algumas especialidades da Ciência Jurídica (Direitos Humanos, Ambiental, Administrativo, Empresarial, Econômico e Atuarial). Assim, no âmbito da proteção ambiental em face do risco e da necessidade de estímulo ao desenvolvimento socioeconômico sustentável, o fomento à constituição de fundos privados (ou público-privados) com robustez, sustentabilidade atuarial e sob fiscalização democrática de agentes estatais, privados, peritos e representantes da sociedade civil também passa pela observância de diretrizes peculiares aos sistemas de seguros e resseguros em escalas nacional e internacional. Sob essa ótica pode-se reconhecer que

As part of an environmental policy for mines, environmental bonds could also be used to incentivize mining companies to improve monitoring systems and management. In this case, an environmental bond is created when corporate funds are deposited in advance of a mining activity and are held in escrow until the end of mining and released when reclamation operations are successfully completed (Gerard 2000). The financial coverage provided by this bond could be based on the relative risk of the mining activity and the potential loss of the environmental services. By making bonds mandatory, companies that do not have the capital to cover potential accidents or propose very risky operations will not be able to go ahead with their initial plans. Hence, they will have to reduce the potential size and/or risk of their operation to move forward. If well planned, this policy could markedly improve enforcement of environmental regulations while encouraging mining corporations to minimize their risks and liability, thereby increasing environmental safeguards. (GARCIA, RIBEIRO, ROQUE, OCHOA-QUINTERO, LAURANCE, 2017) 5

5 Tradução livre dos autores: “Como parte de política ambiental para mineradoras, cauções ambientais poderiam ser utilizadas para incentivar as mineradoras a melhorar os sistemas de monitoramento e manejo. Nestes casos, a caução ambiental é estabelecida quando fundos empresariais são depositados previamente à instalação das atividades do empreendimento e são conservados em contas caucionadas 
Consequentemente, a norma geral nacional que eventualmente for editada na temática da caução ambiental afastaria a eficácia da legislação estadual, em sua normatividade primária ou regulamentar, caso a norma da União fosse mais protetora do que a norma estadual em relação ao meio ambiente e às potencialidades de danos humanitários, ambientais ou histórico-culturais decorrentes de eventual sinistro, sob a incidência e conjugação dos princípios constitucionais relacionados à efetividade da proteção (COSTA, REIS, OLIVEIRA, 2016). Ademais, a norma geral nacional também prevaleceria em sua aplicação nas hipóteses em que a área de impacto (mancha de inundação) ou a zona de autossalvamento transcendessem os limites do território estadual. Ainda assim, aspectos típicos do meio ambiente local-regional e fatores socioeconômicos de natureza peculiares à historicidade das comunidades no território do Estado devem ser sempre considerados nas circunstâncias em que houver a potencialidade de antinomia entre normas gerais nacionais e normas específicas das entidades federativas regionais e locais, o que reforça as suas competências legislativas concorrente suplementar e concorrente de integração.

Em relação ao tema da caução ambiental, há que se destacar alguns aspectos. O primeiro deles diz respeito à generalidade do termo "caução" utilizado na lei mineira (Lei Estadual $n^{\circ} 23.291$, de 2019, artigo $7^{\circ}$, inciso I, alínea "b", e inciso III, alínea "b"). Entretanto, ao se realizar um processo hermenêutico-sistêmico do dispositivo legal, depreende-se que o termo "caução" que está nele previsto expressa a ideia de instituto-garantia contra sinistro difuso. Logo, a utilização das garantias clássicas de natureza real ou fidejussória, ainda que simultaneamente previstas na legislação, não seriam de aplicação mais adequada se considerada a caução ambiental como um instituto-garantia de direitos e deveres difusos. Nenhuma delas serviria, a princípio, para se alcançar o fim almejado com essa modalidade de caução, qual seja, o de garantir, por parte do empreendedor - com a atuação direta ou indireta dos entes estatais -, a imediata assistência e provimento multidimensional às vítimas e às ações de recuperação

aguardando até o final da mineração e devolvido quando as operações de recuperação foram concluídas com sucesso (Gerard 2000). A cobertura financeira concedida por esta caução poderia basear-se nos riscos relativos das atividades minerárias e nas perdas potenciais dos serviços ambientais. A obrigatoriedade das cauções ambientais evitaria que as empresas que não têm o capital necessário para cobrir os gastos potenciais envolvidos em um acidente ou as que propõe operações de grande risco não teriam condições de prosseguir com seus planos iniciais. Assim, eles teriam que reduzir o tamanho potencial e/ou o risco de dar prosseguimento às suas operações. Caso bem planejada, essa política poderia melhorar significativamente o cumprimento legal dos regulamentos ambientais ao mesmo tempo que incentivaria as mineradoras a minimizarem seus riscos e passivos e, consequentemente aumentaria as medidas de proteções ambientais." 
socioambiental para os casos de sinistro e de desativação de barragem. As modalidades de garantia real implicariam na imobilização de capital do empreendedor, por longo tempo e em grande valor. As modalidades de garantia fidejussória exigiriam o comprometimento de terceiros, em grande montante e por longo prazo. Assim, tais garantias seriam desestimuladoras de empreendimentos nesse setor.

Outro aspecto a ser tratado são as modalidades de cálculo do valor do prêmio e da cobertura contratada na caução ambiental. Diversos fatores podem ser conjugados na elaboração dos cálculos, tais como: a) patrimônio, produção, faturamento ou lucro do empreendedor; b) previsão da área impactada e o potencial de dano. Ademais, as formas de integralização da caução e de sua liberação e aplicação também devem ser cuidadosamente analisadas (TORQUETTI; SAWAYA; VEIGA, 2014).

Há ainda outras hipóteses, como a constituição de fundos de caução compostos de recursos advindos de vários empreendedores privados e até de entes públicos, em caráter associativo-consorcial e contributivo, semelhantes a fundos previdenciários. As múltiplas alternativas nessa seara elevam as potencialidades assecuratórias e as de captação de recursos em instâncias nacionais e internacionais, e reduzem custos. Esses fundos podem ser segmentados por atividades socioeconômicas ou também intersetoriais, de modo a serem atuarialmente sustentáveis. Nada impede que os fundos de caução ambiental possam ser especificamente objeto de negociações em mercados distintos e de maneira a não constituírem montantes volumosos de recursos simplesmente imobilizados. Em tais circunstâncias, a liquidez (disponibilidade e acessibilidade) de valores é o recomendável. Sob essa perspectiva, a adequação dos fundos de caução ambiental a regimes de resseguros e às autorizações especiais do Banco Central do Brasil se tornam necessárias.

Enfim, quanto mais recursos forem disponibilizáveis e acessíveis para se minimizarem, de pronto, os efeitos de eventuais sinistros ambientais, de modo célere e sustentável, melhor será para a conjugação de interesses legítimos da atividade socioeconômica e da proteção do meio ambiente.

Por fim, há que se realçar o fato de que a institucionalização da caução ambiental em suas múltiplas nuances tem por finalidade dar resposta imediata às consequências advindas de desastre ambiental por rompimentos e vazamentos de barragens. Por conseguinte, seu foco é a assistência plena às vítimas e a seus parentes e a promoção da recuperação do meio ambiente e do patrimônio histórico-cultural no mais curto prazo possível. Assim, a possibilidade da existência de caução ambiental não é substitutiva 
da responsabilidade jurídica nos âmbitos penais, civis e administrativos. Como dito, sua natureza é a de instituto-garantia em conexão específica com o Direito Ambiental, os Direitos Humanos, o Direito Administrativo, o Direito Empresarial, o Direito Econômico, o Direito Financeiro-Orçamentário e o Direito Constitucional. Nesses termos, é mais um importante instituto-garantia disponibilizado à sociedade e à causa ambiental em suas várias dimensões e repercussões conjunturais e institucionais.

Assim, é muito importante para a efetividade da caução ambiental que ela seja hermeneuticamente classificada como instituto-garantia do direito e do dever difusos em relação à efetividade de proteção do meio ambiente e seus desdobramentos, em especial quanto à utilização de barragens nas atividades socioeconômicas com potencial de impacto e de dano difusos. Há, portanto, que se considerar que a dimensionalidade normativa da garantia se distingue da do direito, pois

Diferentemente do direito - que possui natureza jurídico-substantiva -, a garantia e instituto jurídico dialógico-instrumental, ou seja, ela serve de meio (ex.: ato jurídico perfeito), procedimento (ex.: recorribilidade da decisão judicial) ou processo (ex.: ação de mandado de segurança) para que, na razão dialogicamente construída, o direito individual possa ser subjetivado, o direito individual e o direito coletivo possam ser exercidos, conservados e atualizados, e também para que o sistema jurídico possa ser, legitimamente, preservado e atualizado.

$[\ldots]$

Logo, definimos garantia como instituto jurídico de natureza dialógico-instrumental (meio, procedimento, processo) disponibilizado pelo sistema jurídico aos agentes e instituições de Estado (ex.: Ministério Público), às pessoas de Direito, aos entes atípicos e à coletividade - e passível de ser exercida pelo próprio titular ou até por intermédio de outrem - visando ao alcance das seguintes finalidades [...] prevenção, [...] restituição/reparação, [...] compensação, [...] minimização de efeitos [...]. (OLIVEIRA, 2016, p. 420 e seg.)

Nesse cenário, há também que se destacar que a União - no exercício da competência legislativa concorrente para normas gerais - editou norma geral nacional versando sobre as garantias caucionatórias em relação aos empreendimentos de barragem, nos seguintes termos:

Art. 17. O empreendedor da barragem obriga-se a:

$[\ldots]$

$\S 2^{\circ}$ Sem prejuízo das prerrogativas da autoridade licenciadora do Sisnama, o órgão fiscalizador pode exigir, nos termos do regulamento, a apresentação não cumulativa de caução, seguro, fiança ou outras garantias financeiras ou reais para a reparação dos danos à vida humana, ao meio ambiente e ao patrimônio público, pelo empreendedor de: 
I- barragem de rejeitos de mineração ou resíduos industriais ou nucleares classificada como de médio e alto risco ou de médio e alto dano potencial associado. (Lei Federal $\mathrm{n}^{\circ} 12.334$, de 20 de setembro de 2010 , artigo $17, \S 2^{\circ}$, inciso I, alterado pela Lei Federal $\mathrm{n}^{\circ} 14.066$, de 30 de setembro de $2020^{6}$ )

Em se tratando de norma geral nacional, a Lei Federal $n^{\circ} 14.066$, de 2020, é de natureza conceitual-exemplificativa em relação ao instituto-garantia da caução ambiental para fins de barragens e coexiste, portanto, com a previsão da matéria na Lei Estadual $n^{\circ} 23.291$, de 2019, e suas respectivas regulamentações. Essa perspectiva hermenêutica que tem como premissa de aplicação a norma caucionatória de maior efetividade na proteção ambiental no âmbito das barragens (seja a legislação da União ou a do Estado-membro), resulta da normatividade protetora-emancipadora-plenipotencializadora da Constituição (OLIVEIRA, 2016), e especialmente de seu art. $225, \S 2^{\circ}$, qual seja, "aquele que explorar recursos minerais fica obrigado a recuperar o meio ambiente degradado, de acordo com solução técnica exigida pelo órgão público competente, na forma da lei".

Sob esse parâmetro hermenêutico de eventual antinomia de regimes jurídicos estadual e federal em relação ao instituto-garantia da caução ambiental, é importante registrar que

[...] o 'princípio da primazia do interesse público' tem como duas de suas premissas: a) a precedência do interesse público em relação ao interesse privado, observados os direitos, garantias e deveres fundamentais dos particulares; e b) o devido empenho, por parte dos agentes e instituições do Estado, para com a melhor proteção e realização possíveis dos interesses coletivos da sociedade, historicamente contextualizados.

$[\ldots]$

No caso da proteção ao meio ambiente (interesse público), há a atuação concorrente - convergente suplementar - do "princípio da subsidiariedade" em relação ao "princípio da primazia do interesse público", de modo a fazer prevalecer a norma federal, a estadual ou a municipal que melhor preservar determinado habit sem inviabilizar os outros legítimos interesses públicos da sociedade (local, regional ou nacional), como o acesso ao desenvolvimento econômico autossustentável e a exploração racional das riquezas naturais.

Nesses termos, e observado todo o acervo jurídico brasileiro, somente o caso concreto nos levará a concluir em qual dos entes federativos se assentara a competência para a proteção ambiental. Logo, confirmado o "interesse público" na preservação de um determinado habit, a titularidade e o exercício (prioritário e complementar) da competência para viabilizar a proteção ambiental serão aferidos com base no princípio da subsidiariedade. (OLIVEIRA, 2016, p.376-377)

6 Lei Federal $\mathrm{n}^{\circ} 14.066$, de 30 de setembro de 2020, que alterou a Lei Federal $\mathrm{n}^{\circ} 12.334$, de 20 de setembro de 2010, que estabelece a Política Nacional de Segurança de Barragens destinadas à acumulação de água para quaisquer usos, à disposição final ou temporária de rejeitos e à acumulação de resíduos industriais, cria o Sistema Nacional de Informações sobre Segurança de Barragens. 
Em síntese, positivada a lei estadual (norma concorrente suplementar ou de integração) e, posteriormente, a lei federal (norma concorrente geral nacional), as normas estadual ou federal têm por finalidade última a efetividade dos princípios constitucionais de proteção ambiental-humanitária-cultural por intermédio da unidade e referencialidade do modelo federativo de Estado em seu regime descentralizado e subsidiário de atribuição de competências legislativas aos entes federativos. Nesse processo hermenêutico-concretizador atuam, portanto, e de modo sistêmico, a primazia do interesse público, os critérios de subsidiariedade federativa e a proteção mais efetiva do direito difuso.

\section{CONSIDERAÇÕES FINAIS}

\section{Considerando:}

a) o tema-problema do artigo: qual é o conceito e o alcance normativo do instituto da caução ambiental previsto na legislação estadual de Minas Gerais?

b) o marco teórico-dogmático do artigo: o instituto constitucional da competência legislativa concorrente entre os entes Federativos.

c) as hipóteses de aferição do artigo: a) a maior ou a menor extensão da titularidade e do exercício dessa competência legislativa concorrente pelo Estado de Minas Gerais em relação à caução ambiental; b) a eventual suspensão ou não da eficácia da norma estadual na perspectiva de positivação de norma geral nacional sobre a matéria.

Conclui-se que:

a) a caução ambiental exigida na atividade socioeconômica de mineração e no uso de barragens tem natureza jurídica de instituto-garantia de direito e dever difusos de proteção-emancipação-plenipontencialização ambiental-humanitária-cultural, frente à ocorrência potencial de sinistros, e está em conformidade com a incidência e a conjugação dos princípios constitucionais relacionados à efetividade da proteção;

b) a lei mineira que positivou o instituto-garantia da caução ambiental na utilização de barragens em atividades socioeconômicas de potencial risco ambiental-humanitário-cultural resultou da titularidade constitucional e do exercício adequado da competência legislativa concorrente supletiva por parte do Estado-membro - especialmente no setor da mineração e no contexto histórico-evolutivo de representatividade e peculiaridades deste segmento para a sociedade e o Estado de Minas Gerais; c) a superveniência da lei federal que versa sobre o instituto-garantia da 
caução ambiental nas atividades relacionadas ao uso de barragens assenta-se na titularidade constitucional e no exercício adequado da competência legislativa concorrente geral e nacional da União e tem, nesse contexto, conteúdo conceitual-exemplificativo do referido instituto caucionatório;

d) as particularidades da sociedade e do Estado de Minas Gerais em relação às atividades de mineração e ao uso de barragens autoriza a regulamentação legislativa e a regulação administrativa pormenorizadas do instituto-garantia da caução ambiental, de modo a atender suas peculiaridades locais e regionais em suas diversas conjunturas sociais, ambientais, econômicas e políticas.

e) os dois regimes jurídicos (regional e macronacional) incidentes sobre o instituto-garantia da caução ambiental permanecem válidos e eficazes em sua máxima normatividade, devendo prevalecer, nos vários processos de aplicação jurisdicional, administrativo e fiscalizador - como resultado do processo hermenêutico de concretização -, a norma estadual ou federal (legislada ou administrativo-secundária) de maior efetividade na proteção ambiental-humanitária-cultural, observada a primazia do interesse público e o critério descentralizado e subsidiário de atribuição de competências legislativas aos respectivos entes federativos.

\section{REFERÊNCIAS}

ALEMANHA. República Federal da Alemanha. Lei Fundamental da República Federal da Alemanha. Disponível em: $<\underline{\text { https://www.btg-bestell- }}$ service.de/pdf/80208000.pdf $>$. Acesso em 21/9/2020.

ATALIBA, Geraldo. Normas gerais de direito financeiro e tributário e autonomia dos estados e municípios; limites à norma geral - código tributário nacional. RDP - Revista de Direito Público. São Paulo: Revista dos Tribunais, [s. d.]. Disponível em: $<$ https://edisciplinas.usp.br/pluginfile. php/1894565/mod_resource/content/0/03\%20ATALIBA.\%20Normas $\% 20$ gerais $\% 20 \mathrm{de} \% 20$ direito $\% 20$ financeiro $\% 20 \mathrm{e} \% 20$ tributario.pdf $>$. Acesso em $5 / 9 / 2020$.

ATALIBA, Geraldo. Regime constitucional e leis nacionais e federais. In: CLÉVE, Clèmerson Merlin; BARROSO, Luís Roberto (org.). Doutrinas essenciais: direito constitucional. São Paulo: Saraiva, 2011, Vol. III.

BRASIL. República Federativa do Brasil. Constituição da República Fe- 
derativa do Brasil. Disponível em: < http://www.planalto.gov.br/ccivil 03/ Constituicao/Constituicao.htm $>$. Acesso em 29/9/2020.

BRASIL. República Federativa do Brasil. Supremo Tribunal Federal. Disponível em site oficial: $<\underline{w w w . s t f . j u s . b r}>$

COSTA, Beatriz Souza; REIS, Èmilien Vilas Boas; OLIVEIRA, Márcio Luís de. Fundamentos filosóficos e constitucionais do direito ambiental. Rio de Janeiro: Lumen Juris, 2016.

GARCIA, L.C.; RIBEIRO, D.B.; ROQUE, F.O.; OCHOA-QUINTERO, J.M., LAURANCE, W.F. 2016. Brazil's worst mining disaster: Corporations must be compelled to pay the actual environmental costs. Ecological Applications, 27(1), 2017, pp. 5-9; 2016 by the Ecological Society of America. Disponível em: $<$ https://esajournals.onlinelibrary.wiley.com/doi/ pdf/10.1002/eap.1461>. Acesso em 10/9/2020.

GOMES, Marcelo Kokke; OLIVEIRA, Márcio Luís de. Resposta Socioambiental e Direito dos Desastres: Considerações sobre o Caso Mariana. In: CONPEDI - VI Encontro Internacional - Direitos Humanos, Constitucionalismo e Democracia no Mundo Contemporâneo, 2017, San José Costa Rica. Direitos Humanos, Constitucionalismo e Democracia no Mundo Contemporâneo. Florianópolis - Santa Catarina: CONPEDI - Conselho Nacional de Pesquisa e Pós-Graduação em Direito, 2017. p. 93-114.

HORBACH, Beatriz Bastide. Federalismo alemão fortalece competências estaduais. Observatório constitucional. Revista Consultor Jurídico. Disponível em: <https://www.conjur.com.br/2015-ago-15/observatorio-constitucional-federalismo-alemao-fortalece-competencias-estaduais?impri$\underline{\operatorname{mir}=1}>$. Acesso em 1/9/2020.

HORTA, Raul Machado. Direito Constitucional. $5^{\text {a }}$ ed., atualizada por Juliana Campos Horta. Belo Horizonte: Del Rey, 2010.

OLIVEIRA, Márcio Luís de. A Constituição juridicamente adequada. $2^{\mathrm{a}}$ ed. Belo Horizonte, D’Plácido, 2016.

TORQUETTI, Zuleika S. Chiacchio; SAWAYA, Marta Aparecida M.; VEIGA, Carine Rocha. Modalidades de Garantias Financeiras aplicáveis a empreendimentos industriais e minerários que utilizam barragens de rejeitos, resíduos e reservatórios e de água e sua correlação com as etapas de regularização ambiental. $8^{\circ}$ Congresso Brasileiro de Mina a Céu Aberto 
e $8^{\circ}$ Congresso Brasileiro de Mina Subterrânea. IBRAM - Instituto Brasileiro de Mineração. Belo Horizonte, Minas Gerais, de 6 a 8 de agosto de 2014. Disponível em: <www.ibram.org.br/sites/1300/1382/00005656. pdf $>$. Acesso em 8/9/2020.

WINDHAM-BELLORD, Karen Alvarenga de Oliveira. Direito ambiental, economia verde e conservação da biodiversidade. Belo Horizonte: D’Plácido, 2015.

Artigo recebido em: 05/10/2020.

Artigo aceito em: 16/12/2020.

\section{Como citar este artigo (ABNT):}

OLIVEIRA, M. L.; COSTA, B. S. O Instituto-garantia da caução ambiental e a competência legislativa concorrente na relação federativo-constitucional entre o estado de Minas Gerais e a União. Veredas do Direito, Belo Horizonte, v. 17, n. 39, p. 243-264, set./dez. 2020. Disponível em: http:// www.domhelder.edu.br/revista/index.php/veredas/article/view/1971. Acesso em: dia mês. ano. 